\title{
Properties of Poly(L-leucine) Fiber and Film Prepared by an Improved Method
}

\author{
Seiichi ToKura, Shin-ichiro Nishimura, Kunio NAKAMURA, \\ Shin-ichi KUWAMURA, and Teruo SAITOH \\ Department of Polymer Science, Faculty of Science, Hokkaido University, \\ Kita 10-jo, Nishi 8-chome, Kita-ku, Sapporo 060, Japan
}

(Received March 4, 1983)

\begin{abstract}
KEY WORDS Poly(L-leucine) Fiber / Poly(L-leucine) Film / Trichloroethylene / Reduced Viscosity / Tensile Strength /
\end{abstract}

Membrane of poly(L-leucine), a model peptide for the hydrophobic part of protein, showed prove with respect to properties such as the excellent tensile strength, transparency, and permeability of oxygen or small particles. ${ }^{1}$ Among other polyamino acids, this polypeptide is very close to plastics in its properties owing to hydrophobic side chains consisting of alkyl groups. However, it has been reported that the preparation of poly(L-leucine) fiber and film is very difficult because gelation occurs in benzene even at higher temperatures. ${ }^{2}$ The gel formation could be suppressed either by lowering polymer concentration below $1 \%$ or by adding a high concentration of dichloroacetic acid (DCA) at a temperature higher than $70^{\circ} \mathrm{C}$.

In the present study, trichloroethylene was found to be a much better solvent for poly(L-leucine), and to be able to simplify the procedures for preparing poly(L-leucine) fiber and film. The tensile properties of poly(L-leucine) fiber and film so prepared were compared with those from the benzene-DCA solvent system. Optical rotatory dispersion and viscosity measurements were also carried out.

\section{EXPERIMENTAL}

\section{Poly(L-leucine)}

L-Leucine $N$-carboxylic anhydride (L-Leu NCA) was prepared following the method of Noguchi et $a l^{2,3}$ and allowed to polymerize with $1 / 200 \mathrm{~mol}$. equivalent of triethylamine in benzene at a concentration of $15 \%(\mathrm{w} / \mathrm{v})$ and at $40^{\circ} \mathrm{C}$ for one week.
The number-average molecular weight of the polymer was estimated by $N$-terminal titration ${ }^{2}$ after repeated precipitation by trichloroethylene (TCE) and ethanol.

\section{Spinning Solution}

Two grams of poly(L-leucine) were dissolved in $60 \mathrm{ml}$ of TCE at $50-60^{\circ} \mathrm{C}$ and spun into ethanol at room temperature through a platinum nozzle $(0.2 \mathrm{~mm} \phi, 30$ holes $)$ after the addition of DCA immerdiately before spinning (final concentration of DCA, $7.7 \% \mathrm{v} / \mathrm{v}$ ). The spinning conditions are summarized in Table I.

\section{Preparation of Film}

Poly(L-leucine) film was prepared by coagulating

Table I. Spinning conditions of poly(L-leucine) fiber

\begin{tabular}{|c|c|c|c|}
\hline $\begin{array}{l}\text { Spinning } \\
\text { solution }\end{array}$ & \multicolumn{2}{|c|}{$\begin{array}{l}\text { Polymer concn } \\
\text { DCA concn } \\
\text { Solvent }\end{array}$} & $\begin{array}{l}3.1 \%(\mathrm{w} / \mathrm{v}) \\
7.7 \%(\mathrm{v} / \mathrm{v}) \\
\text { Trichloroethylene }\end{array}$ \\
\hline \multicolumn{3}{|l|}{ Nozzle } & Pt $(0.2 \mathrm{~mm} \phi, 30$ holes $)$ \\
\hline \multicolumn{2}{|c|}{ Coagulation bath } & $\begin{array}{l}1 \text { st } \\
\text { 2nd }\end{array}$ & $\begin{array}{l}\text { Ethyl alcohol }(50 \mathrm{~cm} \text { of length) } \\
\text { Methyl alcohol ( } 75 \mathrm{~cm} \text { of length) }\end{array}$ \\
\hline \multicolumn{3}{|c|}{ Stretching bath } & Hot water $\left(50^{\circ} \mathrm{C}\right)$ \\
\hline \multicolumn{3}{|c|}{ Spinning rate } & $\begin{array}{l}\text { 1st roller; } 6.3 \mathrm{~m} \mathrm{~min}^{-1} \\
\text { 2nd roller; } 8.6 \mathrm{~m} \mathrm{~min}^{-1}\end{array}$ \\
\hline \multicolumn{3}{|c|}{ Spinning temperature } & $\begin{array}{l}\text { Spinning solution; } 50-60^{\circ} \mathrm{C} \\
\text { Coagulation bath; room temp. }\end{array}$ \\
\hline
\end{tabular}


the spinning solution with ethanol after the solution was cast on a glass plate and debubbled at a slightly reduced pressure. The film was dried by pressing it between a pair of filter papers at room temperature after being washed thoroughly with ethanol.

\section{Tensile Strength}

The strain-stress curve was obtained by the method reported previously. ${ }^{4}$

\section{Optical Rotatory Dispersion and Viscosity Mea- surements}

A $0.1 \%$ solution of polymer in TCE was prepared at $40^{\circ} \mathrm{C}$ for measurement of optical rotatory dispersion (ORD) and viscosity. The helix content was estimated using Moffitt-Yang's equation, ${ }^{5}$ and the $b_{0}$ of 630 was considered to indicate a $100 \%$ helix. The reduced viscosity of the polymer solution was determined at $45^{\circ} \mathrm{C}$ and at various polymer concentrations using a Ubbelohde-type viscometer (flow time of TCE: $61.4 \mathrm{sec}$ ).

\section{$X$-Ray Diffraction Pattern}

The fiber pattern of poly(L-leucine) fiber was obtained with $\mathrm{Cu}-K \alpha$ radiation through a $\mathrm{Ni}$ filter from a Toshiba X-ray generator ADX-401. The spacings were calculated from the fiber pattern using silicon powder as the standard. The fiber pattern suggested that poly(L-leucine) molecules are well oriented in the direction of the fiber axis.

\section{RESULTS AND DISCUSSION}

The number-average molecular weight of the poly(L-leucine) sample prepared was estimated to be $9.8 \times 10^{4}$ from the $N$-terminal titration. The polymer was dissolved at $50^{\circ} \mathrm{C}$. Since the helix content estimated in TCE was about $25 \%\left(b_{0}=160, c=0.1\right)$ at $40^{\circ} \mathrm{C}$, the $\alpha$-structure of poly(L-leucine) could hardly be maintained in TCE. However, no destruction of the secondary structure seemed to take place by the addition of DCA, because the value of $b_{0}$ changed little with increasing DCA concentration up to $11 \%(\mathrm{v} / \mathrm{v})$. However, the slope of the reduced viscosity $v s$. polymer concentration curve decreased with the amount of added DCA, although no significant change occurred in intrinsic viscosity, as shown in Figure 1. For this reason, DCA was added in order to reduce the viscosity of the spinning solution. Since, the poly(L-leucine) fiber was prepared at a stretching ratio of 1.37 in hot water despite the relatively lower polymer concentration, the polymer molecules must have orient-

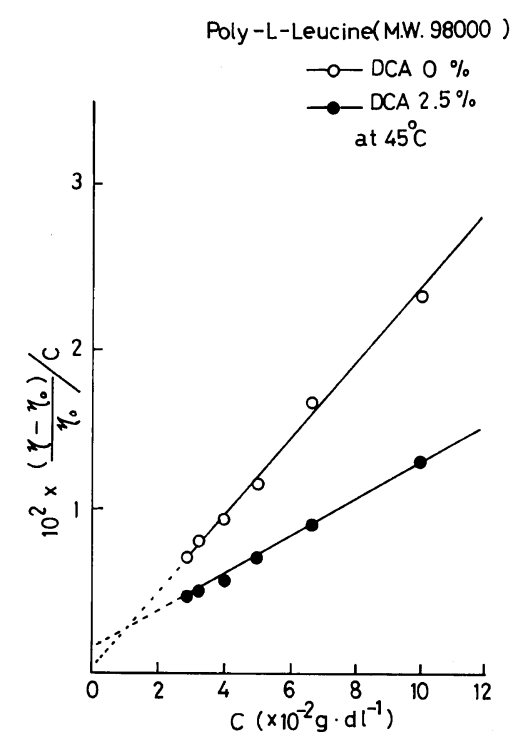

Figure 1. Dependence of reduced viscosity on polymer concentration. A Ubbelohde-type viscometer (flow time for trichloroethylene, $61.4 \mathrm{~s}$ ) was used. Poly(L-leucine) (M.W. 98000): -O-, DCA $0 \%$; - - DCA $2.5 \%$ at $45^{\circ} \mathrm{C}$.

Table II. Tensile properties of poly(L-leucine) fiber

\begin{tabular}{|c|c|c|c|c|}
\hline & \multirow{2}{*}{ Denier } & Young's modulus & \multirow{2}{*}{$\frac{\text { Strength }}{\mathrm{gd}^{-1}}$} & \multirow{2}{*}{$\frac{\text { Elongation }}{\%}$} \\
\hline & & $\mathrm{gd}^{-1}$ & & \\
\hline Dry $\left(20^{\circ} \mathrm{C}, 65^{\circ} \mathrm{RH}\right)$ & 3.32 & 42.2 & 1.37 & 37.2 \\
\hline Wet $\left(20^{\circ} \mathrm{C}, 100 \% \mathrm{RH}\right)$ & 4.82 & 42.4 & 1.32 & 18.4 \\
\hline Wet $\left(90^{\circ} \mathrm{C}, 100 \% \mathrm{RH}\right)$ & 3.68 & 25.4 & 1.00 & 48.0 \\
\hline Knot strength $\left(20^{\circ} \mathrm{C}, 65 \% \mathrm{RH}\right)$ & 2.49 & - & 1.32 & 31.5 \\
\hline
\end{tabular}




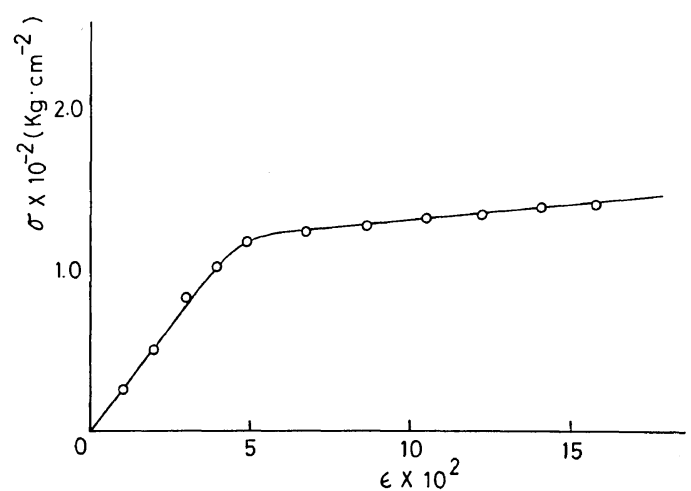

Figure 2. Strain-stress curve of poly(L-leucine) film: sample length, $25 \mathrm{~mm}$; rate, $5 \mathrm{~mm} \mathrm{~min}^{-1}$; full scale, $5 \mathrm{~kg}$; thickness, $0.2 \mathrm{~mm}$; room temperature. Tensile modulus, $2.7 \times 10^{9} \mathrm{dyn}^{-2}$; tensile strength, $1.4 \times 10^{8} \mathrm{dyn}^{-2}$; elongation at break, 0.16 .

ed well in the direction of the fiber axis. The X-ray diffraction pattern of the fiber confirmed this expectation. The spacings of the poly(L-leucine) fiber were calculated as follows: $8.9,4.4,4.0$, and $3.4 \AA$ on the equator (fiber axis) and 4.7, 4.4, 3.2, and $2.7 \AA$ on the meridian. The spacing of $3.4 \AA$ on the equator and that of $4.7 \AA$ on the meridian suggest that the poly(L-leucine) fiber contains much $\beta$ structure as found by Noguchi et al. for copoly( $\gamma$-methyl-L-glutamate/L-methionine)-S-methyl sulfate fiber. ${ }^{6}$

The tensile properties of poly(L-leucine) fiber are listed in Table II. The better tensile strength and elongation in the wet state indicate the advantage of the present procedure, although the dry strength did not change significantly. On the other hand, poly(L- leucine) film prepared under the present simplified conditions promises physical properties better than those prepared from the benzene-DCA system. The plastic flow as in the case of poly(L-leucine) fiber was first observed for the poly(L-leucine) film at higher strains as shown in Figure 2. The film prepared from the benzene-DCA mixed solvent is reported to be brittle and rigid unless converted to a hydrophilic membrane. The transparent film became turbid on absorption of water, but its tensile strength and flexibility changed little.

Further studies on the preparation of fiber from a solution of higher polymer concentration and the permeability of oxygen or small molecules through poly(L-leucine) membranes are now under investigation.

Acknowledgement. The authors are very much indebted to Mitsubishi Rayon Co., Ltd. for providing technical assistance in measuring the fiber properties.

\section{REFERENCES}

1. A. Aiba, N. Minoura, and Y. Fujiwara, Kobunshi Ronbunshu, 39, 299 (1982).

2. J. Noguchi, T. Nakamura, T. Hayakawa, and C. Ohizumi, Kogyo Kagaku Zasshi, 70, 1254 (1967).

3. J. Noguchi, N. Nishi, M. Itaya, and S. Tokura, Kogyo Kagaku Zasshi, 69, 745 (1966).

4. S. Tokura, N. Nishi, and J. Noguchi, Polym. J., 11, 781 (1979).

5. W. Moffitt and J. T. Yang, Proc. Natl. Acad. Sci. U.S.A., 42, 596 (1956).

6. J. Noguchi, N. Kobayashi, K. Tatsukawa, and N. Nishi, Kogyo Kagaku Zasshi, 71, 1748 (1968). 